\title{
Sociodemographic and health related factors associated with poor mental health in midlife Australian women
}

\author{
Sue Outram Lecturer in Health Behaviour Sciences ${ }^{1}$ \\ Gita D. Mishra Senior Research Fellow ${ }^{2}$ \\ Margot J. Schofield Associate Professor of Counselling ${ }^{3}$ \\ ${ }^{1}$ Faculty of Health, University of Newcastle, Australia \\ ${ }^{2}$ Research Institute for Gender and Health, University of Newcastle, Australia \\ ${ }^{3}$ School of Health, University of New England, Australia
}

Address for correspondence: Dr Sue Outram, Faculty of Health, University of Newcastle, Callaghan, New South Wales 2308, Australia.

Tel: 61249246420

Fax: 61249246208

Email: sue.outram@newcastle.edu.au

Key words: psychological distress, women, midlife, sociodemographic factors 


\begin{abstract}
Objective: To examine associations between poor mental health and sociodemographic, psychosocial and health related variables in midlife Australian women.

Method: The random population-based sample comprised 13961 Australian women aged 45-50 years who participated in the baseline postal survey for the Australian Longitudinal Study on Women's Health, conducted in 1996. The outcome measure, poor mental health status, was measured by the Mental Health Index (MH) of the SF-36.
\end{abstract}

Results: Sociodemographic factors associated with poor mental health were low educational levels, being unemployed or engaged solely in home duties, and non English speaking background (European). Health related factors independently associated with poor mental health were having five or more visits to the doctor in the past year, menopausal status (surgical and peri-menopausal), less exercise, and smoking 20 or more cigarettes per day. Among psychosocial variables, low satisfaction with partner or close relationships, low perceived social support outside family, and more life-events over the past 12 months were independently associated.

Conclusion: The findings suggest a number of areas in which preventive interventions could be strengthened to improve quality of life among mid-aged women. These include policy changes to promote and support more education and employment opportunities for women before they reach midlife, increase understanding of the link between health risk behaviours and psychological well-being, and provide counselling services to improve women's relational and psychosocial circumstances. 


\section{Sociodemographic and health related factors associated with poor mental health in midlife Australian women}

Mental health problems cause a substantial burden of morbidity, disability and mortality (Judd, 1996), and are identified as a priority health area in Australia. Mental health problems are the third largest cause of overall disease burden and account for $27 \%$ of total years lost due to disability (Mathers, Vos, \& Stevenson, 1999). While many studies have concentrated on clinical populations, and the social and economic costs of severe mental illness such as schizophrenia (Human Rights and Equal Opportunity Commission, 1993) others have emphasised the costs resulting from a broad spectrum of affective disorders (Croft-Jeffreys \& Wilkinson, 1989; Johnson, Weissman, \& Klerman, 1992). The social and economic costs derive from the high prevalence of mental health problems (Australian Bureau of Statistics, 1998; Mathers et al., 1999), from their severity and chronicity (Mojtabai, 2001), and from their impact on other aspects of life functioning such as work capacity and relationships (Jenkins et al., 1997; Mojtabai, 2001), as well as considerable treatment costs to the health system and community.

Prevalence rates vary, but it has been estimated that one in five Australians will suffer from a significant mental disorder in their lifetime, with anxiety and depression being the most common (Commonwealth of Australia, 1992). The Australian National Mental Health Survey (SMHWB) found an overall 12 month prevalence rate of mental disorders of eighteen per cent (Australian Bureau of Statistics, 1998).

Community mental health surveys have shown 2:1, sometimes even 3:1 female to male ratio of depression and anxiety (Blazer, Kessler, McGonagle, \& Swartz, 1994) and women in midlife have been found in some studies to have higher prevalence rates than in other age-groups (Australian Bureau of Statistics, 1998; UK Royal College of General Practitioners, 1986). Australian women have reported six-month prevalence rates of stress (56.6\%), anxiety (53.1\%), and depression (45\%) (Redman, Hennrikus, Bowman, \& Sanson-Fisher, 1988). These findings highlight the serious magnitude of psychological morbidity among mid-life women.

The current paper examines the broad area of psychological distress rather than any one specific mental disorder, since there is substantial evidence that acute disorders are 
associated with longer term morbidity and subsyndromal symptoms such as minor depression (Broadhead, Blazer, George, \& Tse, 1990; Mojtabai, 2001). Important findings from the US National Comorbidity Survey suggest residual symptoms persist long after the illness episode resolves, and that this can be associated with significant impairment of functioning (Motjabai, 2001). Judd and Akiskal suggest that the natural history of major depression in the community involves "shifting levels of depressive symptom severity with tendency for intermittent chronicity” (2000, p.6).

The current study focuses on mid-life women, since both professionals and women themselves have identified high rates of psychological distress in mid-life, attributed either to the biological changes of menopause (Avis \& McKinley, 1991), or life-stage changes such as “empty nest syndrome” and caring for elderly parents (Bozic, Herman \& Schofield, 1993).

A wide range of factors has been found to be significantly associated with mental health. Sociodemographic variables found to be associated with poor mental health include low socioeconomic status (Blaxter, 1990; Romans-Clarkson, Walton, Herbison, \& Mullen, 1990), female gender (Paykel, 1991), low levels of education (Blazer, Kessler, McGonagle, Swartz, 1994), not being in paid employment (Australian Bureau of Statistics, 1998), poverty and poor housing (Brown, 1978). While associations between urban living and poor mental health have been reported (Jenkins, Lewis, Bebbington et al., 1997), it appears to be country specific as other studies have found no overall urban-rural differences (Robins, Helzer, Weissman et al., 1997). There has been very little documented research in Australia on the mental health of rural and remote Australians, or about the incidence and prevalence of mental health problems among people from non-English speaking backgrounds (NESB) living in the community.

The relationships between marital status, parity and mental health have shown inconsistent results and it is clear that no simple cause-effect conclusions can be made. Recent studies have consistently reported that women who are separated, divorced or widowed, and women who have never married, have higher rates of psychological distress compared with women who are married or in a defacto relationship (Australian Bureau of Statistics, 1998; Jenkins et al., 1997). Poor physical health (Johnson, Weissman \& Kleinman, 1992), being overweight (Brown, Dobson, \& Mishra, 1998), low exercise levels (Brown, Lee, Mishra, \& 
Bauman, 2000), alcohol use and cigarette smoking (Jorm, 1999) have also been associated with poor mental health.

Historically there has been a lack of community mental health data in Australia, although the SMHWB has started to address this deficit across the whole population. The Australian Longitudinal Study on Women's Health, now called Women's Health Australia (WHA) provides an opportunity to investigate mental health and psychological well-being among a more targeted subsection of the Australian population, a representative sample of midlife women. Specifically, the study aimed to determine the independent associations between sociodemographic and health related variables and poor mental health among mid-aged Australia women. Using an age and gender defined sample allows a focus on issues relevant to that sample and for the inclusion of, and control for, socio-demographic and health related variables that have been variously implicated but rarely included in a comprehensive and controlled manner in past research.

\section{Methods}

Sample

Data for this study was collected as part of the baseline survey of the Australian Longitudinal Study on Women's Health (WHA). WHA is a federally funded interdisciplinary longitudinal research project designed to track the health of three cohorts of women over at least twenty years. Random samples of women aged 18-23, 45-50 and 70-75 years in 1996 were selected from the Medicare database by the Health Insurance Commission, with sufficient numbers being selected to enlist 12,000-15,000 women in each age cohort. The sampling scheme included over-sampling of women in rural and remote areas of Australia so that factors influencing their health outcomes could be explored. This paper concerns only the mid-aged cohort.

\section{Procedure}

The selected women were sent a questionnaire by mail in 1996 covering a range of sociodemographic and health related variables. An option for telephone interviews was available for those unable to complete the questionnaire and interpreters were provided. A series of mailed reminders followed but statutory regulations prohibited telephone followup of non-respondents. Details of the recruitment methods and baseline measures have been 
reported elsewhere (Brown, Dobson, Bryson, \& Byles, 1999). The study was approved by the Human Research Ethics Committee of the University of Newcastle.

\section{Measures}

\section{Outcome factor}

Mental health was measured by the 5 item (26 level) mental health index (MH) from the SF-36 (Ware \& Sherbourne, 1992). The MH includes items from the major dimensions of mental health (anxiety, depression, loss of behavioural or emotional control) within a fourweek time frame. A low score indicates feelings of nervousness and depression all the time and a high score indicates the person has felt peaceful, happy and calm. The MH has been found to be as good as the longer MHI-18, as well as the extensively used General Health Questionnaire, at predicting significant mental disorders including major depression, affective disorders generally, and anxiety disorders according to the Diagnostic Interview Schedule (Berwick, Murphy, Goldman, Ware, Barsky, \& Weinstein, 1991; McCabe, Thomas, Brazier, \& Coleman, 1996). A score of 52 and below (out of 100) on the MH was chosen as a cut point for defining poor mental health status (Holmes, 1998).

\section{Study factors}

Women were asked standard sociodemographic questions about their age, highest educational levels achieved, employment status, most recent occupation, country of birth, marital status and the presence of children under 18 living with them. Questions were asked about menopausal status, perceived satisfaction with key relationships (family, friendships, partner), social support (number and quality of emotional support), visits to general practitioners over the past year; and a range of self reported behavioural health characteristics (cigarette smoking, alcohol use, exercise levels). Menopausal status was categorised into pre-menopause, peri-menopause, surgical menopause (hysterectomy and/or oopherectomy) and post-menopause according to classifications used by Avis and McKinlay (Avis and McKinley, 1991).

Three questions measuring different aspects of social support (from the Duke Social Support Index ) (Koenig, Westlund, George, Hughes, Blazer, \& Hybels, 1993) asked about the number of people in the local area they could depend on other than family members (none, 1-2, more than 2), whether they felt understood by friends or family, and whether they could talk about their deepest problems with these people (hardly ever, some of the 
time, or most of the time). Women were asked to rate their satisfaction with family relationships, their partner/closest relationship and friendships on a scale of very satisfied; satisfied; dissatisfied; very dissatisfied. For analysis these were collapsed these into “satisfied” and “dissatisfied”.

BMI was calculated from self-reported height and weight and corrected for self-reporting bias (Waters, 1993) [Estimated weight $=1.007 \mathrm{x}$ reported weight in kg; estimated height $=$ $19.208+(0.879 \mathrm{x}$ height in $\mathrm{cm})]$. Alcohol consumption was determined from questions asking how many days per week the women usually drank alcohol and how many drinks per day. The responses were used to categorise women as: non-drinker; no risk; and low (two standard drinks daily) to high risk (more than 4 standard drinks per day). Smoking status was categorised as: never smoked; ex-smoker; currently smoke less than 20 per day; and currently smoke 20 or more per day. Level of exercise was determined from questions about the frequency of engaging in vigorous and less vigorous exercise and the resulting score summed over all questions, ranged from 0 to 80 and was treated as a continuous variable (Brown et al., 2000). Physical health status was determined by using the Physical Component Summary Score (PCS) of the SF-36 (Ware \& Sherbourne, 1992).

A life events score was calculated by the number of life events the woman recorded in the past year from a list of 28 items. This list was adapted from the work of Norbeck (1984) and developed for the midlife group in the WHA study.

\section{Analysis}

Initial analyses involved Chi-square tests on all categorical variables of interest. For continuous variables, t-tests were used. The calculation of sample percentages was weighted to account for oversampling in rural and remote areas. For those found to be significantly related to the dichotomised variable "poor mental health", crude odds ratios were calculated. Multiple logistic regression was used to estimate the associations between these variables and poor mental health after adjustment for all other factors. The analyses were performed using PROC LOGISTIC in SAS (SAS Institute, c1990). 


\section{Results}

\section{Respondents}

The respondents were 13961 women aged 45-50 giving a response rate of 54 per cent. The women were broadly representative of Australian women in that age range but compared to the 1996 National Census, more women in the study were tertiary educated and fewer were women of non-English speaking background. The women's profile is available elsewhere in more detail (Brown et al., 1999).

\section{Socioeconomic and health related variables}

All factors described above were significantly related in the univariate analyses to poor mental health $(\mathrm{p}<0.001)$ except age, and whether the women had children under 18 living with them (these two variables have thus been omitted from the table). Table 1 shows the crude and adjusted odds ratios for the relationship between poor mental health and sociodemographic, health, behavioural and psychosocial variables.

After adjusting for other factors in the multivariate logistic regression analysis, sociodemographic factors which were statistically significantly related to poorer mental health were: low educational levels, non-employed status (home duties only, being unemployed, being unable to work due to sickness) relative to full-time paid work, being born in Europe and being a manual worker compared with being in sales or personal service. Among health variables, women who had five or more consultations with their doctor in the last 12 months had over twice the odds of poor mental health compared with those not visiting their doctor at all, and those with surgical or peri-menopause status had a higher odds of poor mental health compared with pre-menopausal women.

Low satisfaction with partner, family and friendships, low perceived social support outside family, and feelings of being poorly understood were significantly associated with poor mental health. For lifestyle related variables, lower levels of exercise and smoking 20 or more cigarettes per day were significantly related to poor mental health. An increase in one life-event resulted in a proportionate one-unit decrease in mental health scores. 


\section{Discussion}

The study describes with a considerable degree of confidence the sociodemographic, health, behavioural and psychosocial variables significantly related to poor mental health in a representative sample of midlife Australian women. It supplements the scant body of research on poor mental health in community, compared with clinical, populations in Australia. The strengths of the study include: the large sample size which provides good statistical power and allows adjustment for many confounding variables; random sampling from the national Medicare database, the most up-to-date sampling frame for the Australian population; and despite a response rate of 54 per cent, population comparisons indicate a sample that is largely representative of Australian women of this age. The study provides a number of valuable directions for appropriate intervention strategies to improve the psychological well-being and quality of life of mid-aged women.

The study has some limitations. First, it utilises cross sectional data and therefore cannot indicate causal relationships. For instance, the strong relationship between satisfaction with relationships and mental health may well be mutually determined: poor mental health is likely to reduce the quality of close relationships, and relationship difficulties may well lead to greater psychological distress. The longitudinal nature of the WHA study will allow us to better examine these potential causal relationships as women are followed over time.

A second potential limitation is the possibility that inclusion of so many variables may lead to over-control of the statistical model. Some of the variables that were statistically significant had small odds ratios, however the decision was made to include them in the analysis at the 0.05 level because this was an exploratory study and we wanted to control for possible confounders. Furthermore, all variables included had been identified in previous studies.

The overall design of the study gives confidence that greater psychological distress in midlife women is associated with some socio-demographic variables (lower education, non-employment and NESB (European) country of birth, as well as psychosocial and health risk variables and health service use. These are discussed in turn. 
Lower educational levels and not being in the paid workforce (ie home duties, unemployed and looking for work) signficantly predicted poor mental health, consistent with previous research (Blazer et al, 1994; Williams, McGee et al 1997; Australian Bureau of Statistics, 1998). Strategies aimed at increased educational opportunities for young women should continue to be implemented, as well as re-entry opportunities for mid-aged women. It appears that paid work is advantageous to women's mental health and increased employment opportunities for women should be high on the political agenda. However caution should be exercised in policy formation as emerging research indicates there may be differential health effects of paid work on different groups depending on class, race, marital status (Brown \& Moran, 1997; Elliot \& Huppert, 1991; Waldron \& Jacobs, 1988) and the number of hours worked (Bryson \& Warner-Smith, 1998). As with the marital status variable, it may be the satisfaction with one's work that is most closely related to mental health.

\section{Country of birth.}

Poorer mental health was found in NESB women born in Europe, and marginally for Asian women, than in women born in Australia or other English speaking countries, supporting previous research in Australia (Bui \& Bertelli, 1990). Although our data collection method allowed for telephone surveys using interpreters for women who were not fluent in English, they were, nevertheless, not adequately represented in our final sample. It is probable that newer migrants and those less fluent in English were less represented.

\section{Geographic area.}

Contrary to overseas (UK) research that reported poorer mental health in urban areas (Jenkins et al., 1997), there were no significant differences found between the mental health of women living in urban, rural and remote geographical areas after adjustment for potential confounders. As one possible explanations for this result, we note that the definition of rural in this study was very broad, encompassing a wide range of different geographical areas from large rural towns to small country areas and farms and this may have distorted results. Furthermore, the implications of living in a rural area in Australia are very different from living in rural areas of the UK, given the much greater distances and isolation involved in rural Australia, as well as very different levels of access to health and other services. 


\section{Marital status}

The previous research finding, that women who are married or living in a defacto relationship have better mental health (Australian Bureau of Statistics, 1998; Jenkins et al., 1997), was not supported in this study. While marital status was highly significant at the univariate level, its significance completely disappeared in the multivariate analysis. Further examination revealed that the correlation with satisfaction with relationships partially accounted for this effect, satisfaction remaining statistically significant in the multivariate analysis. Women with poor satisfaction in relationships had more psychological distress. As noted earlier, it was not possible to determine the causal direction of this finding. Both social support and satisfaction with key relationships were strongly associated with mental health and indicate areas for further research. It is also possible that differences in measurement or sampling accounted for some of the difference in findings.

\section{Menopausal status.}

As in other cross-sectional studies (Dennerstein, Smith, Morse et al., 1993; McKinlay, McKinlay, \& Brambilla, 1987), peri-menopausal women or women who had undergone surgical menopause were more likely to have poor mental health than other midlife women, although the effect was considerably reduced after taking other factors into account. However recent prospective studies have challenged the implication that there may be a causal connection here. These longitudinal studies have found that most peri-menopausal women are no more likely than pre-menopausal women to have poor mental health unless they had pre-existing poor mental health, physical health problems or an overly long menopause (longer than 27 months) (Avis, Brambilla, McKinlay \& Vass, 1994).

Furthermore, longitudinal research suggests that hysterectomy does not lead to greater psychological distress but rather that poor mental health may be a cause rather than a consequence of surgery for this group of women (McKinlay et al., 1987). Reasons for the difference in findings between cross-sectional and longitudinal studies are not clear. It is possible that there may be country or cohort variations. However, there is the potential to further examine this as part of the longitudinal WHA study.

\section{Social support and satisfaction with relationships.}

Low social support and dissatisfaction with key relationships (partner, family, friendships) significantly predicted poor mental health in keeping with previous findings (Romans et al., 
1993; Salokangas, Mattila, \& Joukamas, 1988). The consistent finding of a link between the quality of relationships and mental health is important as it points to important intervention opportunities outside the medical arena, and highlights the need to examine a broader range of policies and services to support women in midlife who are at risk of being lonely and isolated and in unsatisfactory relationships (Barnes, Ikeda, \& Kresnow, 2001). Providing better opportunities for re-entry into meaningful work, greater social and community support networks, and greater access to relationship counselling services may all have a place in improving the mental health of mid-life women and at potentially lower cost to the community than repeated use of expensive medical visits.

\section{Lifestyle.}

Lifestyles involving greater health risk behaviours do appear to be associated with greater pyschological distress, not only in this study, but in previous research (Brown et al., 1999; Jorm, 1999). We found that women who smoke 20 or more cigarettes per day, and women who have low exercise levels are more likely to have poor mental health. What is promising about this is the potential to alter these effects through public health interventions. For instance, research shows that exercise interventions can improve mental health, especially depression (Slaven \& Lee, 1997). Such findings can inform mental health promotion interventions, raising awareness of the benefits of exercise. Community participation programs can serve to increase actual participation. What is needed is a comprehensive approach which addresses lifestyle at the community level and supports development of healthier behaviours.

\section{Life events.}

The accumulation of life events within a 12 month period is a well documented risk factor for poor mental health (Brown \& Harris, 1989; Kendler, Kessler, Neal, Health, \& Eaves, 1993). Our study confirms that women in mid-life who experience more life events are at greater risk, supporting our conclusion that provision of more community-based and psychosocial support services for women may be an appropriate preventive intervention to ease the impact of multiple life events. There is a small but increasing number of evidence based interventions for adverse life events to prevent poor mental health outcomes (National Mental Health Promotion and Prevention Working Party, 1999), and there is increasing evidence for effective interventions for primary, secondary and tertiary prevention in mental health (Raphael \& Burrows, 1995). 


\section{Health care utilisation.}

Women who visited the GP five times or more in the last year compared with women who had not been to the doctor at all, had higher odds of poorer mental health. Furthermore, it has been well documented that psychosocial reasons underlie a large proportion of doctor visits and that doctors are poor at detecting psychological distress and the psychosocial issues (Goldberg and Bridges, 1988). Given that family doctors are a first (and repeated) port of call for many women in distress, we need to examine policies which determine service delivery options and the availability of appropriate services to women. The knowledge, for example, that women who have low exercise levels or who smoke more than 20 cigarettes per day, or who have unsatisfactory marital relationships are more likely than other women to have poor mental health, could operate as a trigger for detecting mental health problems in clinical populations such as GP surgeries, hospital outpatients and surgical consultations.

Detection and appropriate follow up treatment in primary care settings or referral to other services, where indicated, may improve quality of life for these women. However detection without adequate management may be detrimental. There has been criticism by women of doctors' lack of interest in, and treatment of, mental health problems (Belle, 1982; Miles, 1988). Lack of time in the consultation (Stevens \& Douglas, 1988) and an over reliance on psychotropic medication as a response to psychological distress has been reported (Rogers \& Pilgrim, 1993). There is also varying evidence of the effectiveness of treatment for psychological disorders in general practice (Schulberg, Katon, Simon, \& Rush, 1998). Therefore effort should be directed at increasing the skills of primary care practitioners, as well as developing better referral pathways to appropriately trained professionals. For instance, counselling has been recognised as a first line of treatment for minor to moderate depression and general psychological distress (NHMRC, 1997), yet there are few policies in place to ensure competent and affordable provision of counselling services, especially to more vulnerable sections of the community. By contrast, in the United Kingdom, more than half of all general practices have counselling services available (Mellor-Clark, 2000).

\section{Conclusions}

This study examined factors associated with psychological distress among Australian women in mid-life using multivariate analyses. Social support, social networks and the 
influence of key relationships emerged as important factors associated with mental health and well-being which are amenable to preventive actions through community-based programs, health promotion activities and provision of counselling and support services. The positive relationships between mental health and both education and employment suggest that policies are needed to facilitate women's re-entry into the workforce after child-bearing or child-rearing. Greater health service use among women with greater psychological distress suggest that doctors may have an important role in orienting women to appropriate alternative services which can better address the underlying causes of their distress. Future data, which will become available through the longitudinal phase of the WHA study, will help clarify causal relationships and the impact of intervening factors.

\section{Acknowledgements}

Women's Health Australia is a national initiative and was conceived and developed by groups of inter-disciplinary researchers at the Universities of Newcastle and Queensland, and is funded by the Commonwealth Department of Health and Aged Care. Presently, researchers involved in the project come from numerous Disciplines, Departments and Faculties from six Universities across Australia. Professor Jill Cockburn gave valuable comments on this paper. 


\section{References}

Australian Bureau of Statistics. (1998). Mental health and wellbeing profile of adults:

Australia 1997. Canberra: Australian Bureau of Statistics.

Avis, N., and McKinley, S. (1991). A longitudinal analysis of women's attitudes towards the menopause: results from the Massachussettes Women's Health Study. Maturitis, 13, 65-69.

Avis, N.E., Brambilla, D., McKinlay, S.M., and Vass, K. (1994). A longitudinal analysis of the association between menopause and depression: results from the Massachusetts Women's Health Study. Annals of Epidemiology, 4, 214-220.

Barnes, L.S., Ikeda, R.M., and Kresnow, M. (2001). Help-seeking behavior prior to nearly lethal suicide attempts. Suicide \& Life-Threatening Behavior, 32, 68-76.

Belle, D. (1982). Lives in stress: women and depression. Beverly Hills: Sage Publications.

Berwick, D.M., Murphy, J.M., Goldman, P.A., Ware, J.E., Barsky, A., and Weinstein, M.C. (1991). Performance of a five-item mental health screening test. Medical Care, 29, 169 176.

Blaxter, M. (1990). Health and lifestyles. London: Routledge.

Blazer, D.G., Kessler, R.C., McGonagle, K.A., and Swartz, M.S. (1994). The prevalence and distribution of major depression in a national community sample: the national comorbidity study. American Journal of Psychiatry, 151, 979-986.

Bozic, S., Herman, H., and Schofield, H. (1993). A profile of carers in Victoria. Melbourne: University of Melbourne: Victorian Health Foundation.

Brown, G.W. (1978). Social origins of depression: a study of psychiatric disorders in women. London: Tavistock.

Brown, G.W., and Harris, T. (1989). Life events and illness (p.496). New York: The Guilford Press. 
Brown, G.W., and Moran, P.M. (1997). Single mothers, poverty and depression. Psychological Medicine, 27, 21-33.

Brown, W., Dobson, A., and Mishra, G. (1998). What is the healthy weight range for middle-aged women? International Journal of Obesity, 22, 520-528.

Brown, W., Dobson, A., Bryson, L., and Byles, J. (1999). Women's Health Australia: update on the progress of the main cohort studies. Journal of Women's Health \& Gender-Based Medicine, 8(5), 681-688.

Brown, W., Lee, C., Mishra, G., and Bauman, A. (2000). Leisure time physical activity in Australian women: relationship with well-being and symptoms. Research Quarterly for Exercise and Sport, 71(3), 206-216.

Bryson, L. and Warner-Smith P. (1998). Employment and women's health. Just Policy, 14, 3-14.

Bui, T. and Bertelli, L. (1990). A profile of Indo-Chinese communities in Australia. In D. Nguyen, L. Kahill \& L. Bertelli (Eds.), Australian and Indo-Chinese health issues. Melbourne: Australian Association of Vietnamese Studies.

Commonwealth of Australia. (1992). The national mental health policy. Canberra: AGPS. Croft-Jeffreys, C., and Wilkinson, G. (1989). Estimated costs of neurotic disorder in UK general practice 1985. Psychological Medicine, 19, 549-558.

Dennerstein, L., Smith, A.M.A., Morse, C., et al. (1993). Menopausal symptoms in Australian women. Medical Journal of Australia, 159, 232-236.

Elliot, B.J., and Huppert, F.A. (1991). In sickness and in health: associations between physical and mental well-being, employment and parental status in a British nationwide sample of married women. Psychological Medicine, 21, 515-524.

Goldberg, D. \& Bridges, K. 1988, Somatic presentation of psychiatric illness in primary care setting, Journal of Psychosomatic Medicine, 32, 137-144. 
Ho, B.C., Andreasen, N.C., Flaum, M., Nopoulos, P., and Miller, D. (2000). Untreated initial psychosis: its relation to quality of life and symptom remission in first-episode schizophrenia. American Journal of Psychiatry, 157, 808-815.

Holmes, W.C. (1998). A short, psychiatric, case finding measure for HIV seropositive outpatients: performance characteristics of the 5-item mental health subscale of the SF20 in a male, seropositive sample. Medical Care, 36, 237-243.

Human Rights and Equal Opportunity Commission. (1993). Human rights and mental illness, report of the national inquiry into the human rights of people with mental illness. Canberra: AGPS.

Jenkins, R., Lewis, G., Bebbington, P., et al. (1997). The national psychiatric morbidity surveys of Great Britain - initial findings from the household survey. Psychological Medicine, 27, 775-789.

Johnson, J., Weissman, M., and Klerman, G. (1992). Service utilisation and social morbidity associated with depressive symptoms in the community. Journal of the American Medical Association, 267, 1478-1483.

Jorm, A.F. (1999). Association between smoking and mental disorders: results from an Australian national prevalence study. Australian and New Zealand Journal of Public Health, 23, 245-248.

Judd, L.L. (1996). Socioeconomic burden of subsyndromal depressive symptoms and major depression in a sample of the general population. American Journal of Psychiatry, 153, 1411-1417.

Judd, L.L., Akiskal, H.S. (2000). Delineating the longitudinal structure of depressive illness: beyond clinical subtypes and duration thresholds. Pharmacopsychiatry, 33, 3-7. 
Kendler, K.S., Kessler, R.C., Neal, M.C., Health, A.C., and Eaves, L.J. (1993). The prediction of major depression in women: towards an integrated etiologic model. American Journal of Psychiatry, 150, 1139-1148.

Koenig, H., Westlund, R.E., George, L., Hughes, D.C., Blazer, D.G., and Hybels, C. (1993). Abbreviating the Duke Social Support Index for use in chronically ill elderly individuals. Psychosomatics, 34, 61-69.

Mathers, C., Vos ,T. and Stevenson, C. (1999). The Burden of disease and Injury in Australia. Australia Institute of Health and Welfare cat. No PHE 17. AIHW: Canberra. McCabe, C.J., Thomas, K.J., Brazier, J.E., and Coleman, P. (1996). Measuring the mental health status of a population: a comparison of the GHQ-12 and the SF-36 (MHI-5). British Journal of Psychiatry, 169, 516-521.

McKinlay, J.B., McKinlay, S.M., and Brambilla, D. (1987). The relative contributions of endocrine changes and social circumstances to depression in mid-aged women. Journal of Health and Social Behaviour, 28, 345-63.

Mellor-Clark, J. (2000). Counselling in Primary Care in the Context of the NHS Quality Agenda: The Facts. Rugby: British Association of Counselling and Psychotherapy. Miles, A. (1988). Women and mental illness: the social context of female neurosis. Great Britain: Wheatsheaf Books Limited.

Motjabai, R. (2001). Residual symptoms and impairment in major depression in the community. American Journal of Psychiatry, 158, 1645-1651.

National Health and Medical Research Council. Depression in young people: A guide for mental health professional. NHMRC, 1997. URL: http://www.health.gov.au:80/nhmrc/publications/synopses/cp39syn.htm. Accessed 30 January, 2003. 
National Mental Health Promotion and Prevention Working Party. (1999). Mental health promotion and prevention national action plan. Canberra: Commonwealth Department of Health and Aged Care, Commonwealth of Australia.

Norbeck, J.S. (1984). Modification of life event questionnaires for use with female respondents. Researching in Nursing and Health, 7, 61-71.

Paykel, E.S. (1991). Depression in women. British Journal of Psychiatry, 158, 22-29.

Raphael, B., and Burrows, G. (1995). Handbook of studies of preventive psychiatry (p.687). Amsterdam: Elsevier Science.

Redman, S., Hennrikus, D., Bowman, J., and Sanson-Fisher, R. (1988). Assessing women's health needs. Medical Journal of Australia, 148, 123-127.

Robins, L.N., Helzer, J.E., and Weissman, M.M., et al. (1984). Lifetime prevalence of specific psychiatric disorders in three sites. Archives of General Psychiatry, 41, 949-958.

Rogers, A. and Pilgrim D., (1993). Service users' views of psychiatric treatments. Sociology of Health and Illness. 15, 612-631.

Romans-Clarkson, S.E., Walton, V.A., Herbison, G.P., and Mullen, P.E. (1990).

Psychiatric morbidity among women in urban and rural New Zealand: psycho-social correlates. British Journal of Psychiatry, 156, 84-91.

Romans, S.E., Walton, V.A., McNoe, B., Herbison, G.P., and Mullen, P.E. (1993). Otago women's health survey 30-month follow-up I: onset patterns of non-psychotic psychiatric disorder. British Journal of Psychiatry, 163, 733-738.

Salokangas, R., Mattila, V., and Joukamas, M. (1988). Intimacy and mental disorder in late middle age. Acta Psychiatr Scand, 78, 555-560.

SAS Institute. (c1990). SAS/STAT user's guide: d Cary. 
Schulberg, H.C., Katon, W., Simon, G.E., and Rush, J.A. (1998). Treating major depression in primary care practice: an update of the agency for health care policy and research practice guidelines. Archives of General Psychiatry, 55, 1121-1127.

Slaven, L. and Lee, C. (1997). Mood and symptom reporting among middle-aged women: the relationship between menopausal status, hormone replacement therapy, and exercise participation. Health Psychology, 16, 203-208.

Stevens, I.D., and Douglas, R.M. (1988). Dissatisfaction in general practice: what do patients really want? The Medical Journal of Australia, 148, 280-282.

UK Royal College of General Practitioners. (1986). Morbidity statistics from general practice 1981-2 third national survey. London: HMSO.

Waldron, I., and Jacobs, J.A. (1988). Effects of labour force participation on women's health: new evidence from a longitudinal study. Journal of Occupational Medicine, 30, 977-983.

Ware, J.E., and Sherbourne, C.D. (1992). The MOS 36 item short-form health survey (SF36): conceptual framework and item selection. Medical Care, 30, 473-481.

Waters, A.M. (1993). Assessment of self-reported height and weight and their use in the determination of body mass index. Canberra: Australian Institute of Health \& Welfare. Williams, S., McGee, R., Olaman, S., and Knight, R. (1997). Level of education, age of bearing children and mental health of women. Social Science \& Medicine, 45, 827-836. 
Table 1: Percentage of sociodemographic and health related factors, crude and adjusted odds ratios and $95 \%$ confidence intervals related to poor mental health in women 45 - 50 years old

Odds Ratio (95\% Confidence Interval)

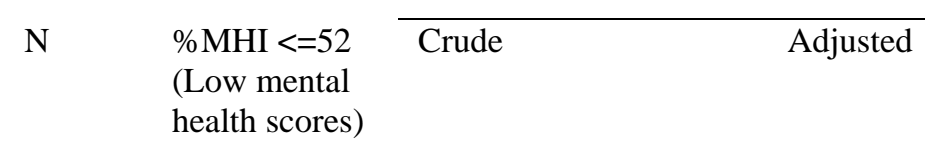

total number
Demographics:
Area of residence

13961

16.3

urban

rural

remote

\section{6}

7883

944

16.8

14.9

13.6

Highest qualification

no formal

2299

secondary school

6480

trade/apprenticeship/ certificate/

diploma

university degree

2699

2269

24.5

15.7

13.5

12.7

1.00

$0.87(0.79-0.96)$

$0.78(0.64-0.95)$

1.00

$0.95(0.84-1.08)$

$1.10(0.85-1.43)$

\section{Employment status}

full - time paid

part - time, work without pay,

unpaid voluntary

home duties only

unemployed, looking for work,

unable - work due - sickness

studying, retired, other

5035

5116

14.0

12.8

2203

20.4

730

40.0

$367 \quad 20.1$

1.00

$0.57(0.51-0.64)$

1.00

$.48(0.41-0.56)$

$0.82(0.70-0.96)$

$0.75(0.61-0.91)$

$.45(0.38-0.52)$

$0.68(0.85-0.86)$

Main occupation

machine/manual

never had a job/others

trade/admin

sales/personal

manager/professional/para

\section{Country of birth}

Australia

other English speaking

Europe (NESB)

Asia

others

$217 \quad 23.0$

\section{Marital status}

married/defacto

div/ sep/wid

single

$\begin{array}{ll}11117 & 14.4 \\ 2116 & 24.7 \\ 536 & 22.3\end{array}$

$536 \quad 22.3$
1.00

$0.91(0.81-1.02)$

1.00

0.98 (0.85 - 1.14)

1.59 (1.39 - 1.81)

$1.54(1.29-1.83)$

4.12 (3.49 - 4.88)

$2.15(1.70-2.71)$

1.54 (1.21 - 1.97)

$1.00(0.72$ - 1.39)

1.00

$0.95(0.74-1.22)$

$0.64(0.55-0.74)$

$0.65(0.56-0.77)$

0.55 (0.48 - 0.63)

1.00

$0.88(0.63-1.24)$

$0.86(0.71-1.04)$

$0.77(0.63-0.96)$

$0.86(0.70-1.06)$

1.00

$0.86(0.76-0.99)$

1.00

$1.60(0.38-1.85)$

$0.97(0.81-1.17)$

$0.76(0.59-0.93)$

$1.42(1.14-1.78)$

$0.64(0.41-1.00)$

1.54 (0.91 - 2.63)

1.57 (1.14 - 2.17)

NS

$1.3(0.7-1.9)$

$1.4(0.8-2.2)$
1.00

1.95 (1.74-2.18)

$1.70(1.38-2.10)$ 
Socioeconomic and health related Page 22 of 23

Odds Ratio (95\% Confidence Interval)

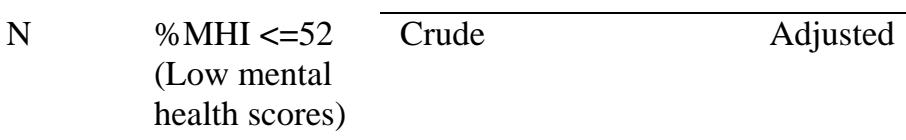

\section{Health related variables \\ Visits - GP in past year}

0 visit

1083

$\begin{array}{ll}1083 & 9.0 \\ 8569 & 11.3\end{array}$

1.00

$1.29(1.03-1.61)$

1.00

five or more

$4118 \quad 28.4$

$4.01(3.22-4.99)$

$0.93(0.73-1.19)$

$2.09(1.62-2.70)$

\section{Menopausal status}

pre

$4506 \quad 12.1$

1.00

1.00

surgical

3115

21.8

$2.03(1.79-2.29)$

$1.27(1.84-1.49)$

peri

16.7

$1.45(1.28-1.65)$

$1.21(1.03-1.42)$

post

1154

18.3

$1.63(1.37-1.94)$

$1.10(0.88-1.38)$

Satisfaction with partner

satisfied

$11022 \quad 12.2$

1.00

3.52 (3.19- 3.89)

1.00

dissatisfied

$2650 \quad 32.8$

1.00

1.00

satisfied

$12356 \quad 13.1$

43.0

$5.01(4.45-5.63)$

$1.68(1.41-2.00)$

Satisfaction with friendships

satisfied

$12520 \quad 13.5$

1.00

1.00

dissatisfied

$1242 \quad 36.6$

3.50 (3.09 - 3.96)

$1.42(1.18-1.72)$

No of people close (not family)

none

$2206 \quad 27.6$

1 to 2

5292

27.6

1.00

1.00

more than 2

6338

10.8

$0.58(0.28-0.36)$

$0.82(0.69-0.0 .96)$

$0.32(0.28-0.36)$

$0.66(0.55-0.80)$

Can talk about deepest problems with family \& friends

hardly ever

1.00

1.00

sometimes

8302

10.8

$0.54(0.48-0.62)$

$1.03(0.86-1.23)$

$0.24(0.21-0.28)$

$0.82(0.67-1.01)$ 
Socioeconomic and health related Page 23 of 23

\begin{tabular}{|c|c|c|c|c|}
\hline & \multirow[b]{2}{*}{$\mathrm{N}$} & \multicolumn{3}{|c|}{ Odds Ratio (95\% Confidence Interval) } \\
\hline & & $\begin{array}{l}\% \text { MHI }<=52 \\
\text { (Low mental } \\
\text { health scores) }\end{array}$ & Crude & Adjusted \\
\hline \multicolumn{5}{|l|}{ Smoking status } \\
\hline ex - smoker & 3876 & 14.6 & $1.07(0.96-1.20)$ & $0.90(0.78-1.04)$ \\
\hline less than $20 /$ day & 1016 & 20.2 & $1.34(1.34-1.87)$ & $1.14(0.91-1.43)$ \\
\hline more than 20 /day & 1357 & 28.9 & $2.55(2.22-2.91)$ & $1.42(1.18-1.70)$ \\
\hline Alcohol & & & & NS \\
\hline non - drinker & 2064 & 18.9 & 1.00 & 1.00 \\
\hline no risk & 10847 & 15.1 & $0.77(0.68-0.86)$ & $0.92(0.78-1.09)$ \\
\hline low to high risk & 867 & 22.9 & $1.27(1.05-1.54)$ & $1.16(0.88-1.53)$ \\
\hline \multicolumn{5}{|l|}{ Exercise } \\
\hline very low & $\begin{array}{l}4013 \\
4205\end{array}$ & $\begin{array}{l}22.3 \\
16.5\end{array}$ & 1.00 & 1.00 \\
\hline low to moderate & $\begin{array}{l}4205 \\
3469\end{array}$ & $\begin{array}{l}16.5 \\
12.2\end{array}$ & $0.69(0.61-0.77$ & $0.80(0.70-0.93)$ \\
\hline moderate to high & 3469 & 12.2 & $0.48(0.43-0.55)$ & $0.60(0.51-0.71)$ \\
\hline very high & 2109 & 11.1 & $0.43(0.37-0.51)$ & $0.62(0.51-0.75)$ \\
\hline PCS $^{\#}$ & & & & NS \\
\hline-3.8 & 13128 & & $0.96(0.96-0.97)$ & $0.99(0.99-1.01)$ \\
\hline BMI $^{\#}$ & & & & NS \\
\hline 0.6 & 13216 & & $1.02(1.01-1.03)$ & $0.99(0.98-1.01)$ \\
\hline \multicolumn{5}{|c|}{ Life events summary scores ${ }^{\#}$} \\
\hline 1.4 & 13957 & & $1.21(1.19-1.23)$ & $1.12(1.09-1.14)$ \\
\hline
\end{tabular}

\# Mean difference in scores between women with and without low mental health.

* $\mathrm{N}$ varies due to missing values

Not significant (NS) p-value $>0.05$. 